\section{A new kid on the block in corporate dentistry}

Dental Partners is the UK's newest dental corporate and has entered the world of UK dentistry with a new and refreshingly different outlook that is rewriting the way in which corporate dentistry is viewed.

Backed by August Equity, Dental Partners is a fast-growing organisation that has in place a proactive programme of growth and has already acquired the Genesis Group (based largely in Derbyshire) and two mixed practices in Sheffield.

For practice owners looking to relieve some of the pressures of working in practice, Dental Partners offers a perfect solution: a corporate looking for growth opportunities, with the business know-how to compete in today's competitive environment, but which also has the best interests of staff and patients at heart.

Far from a faceless corporate giant, Dental Partners aims to recruit the brightest dental talent and nurture a clinical environment that ensures all their practices deliver the very best and most appropriate dental care to patients.

Find out more at www.dentalpartners.co.uk or email contact@dentalpartners.co.uk.

\section{The injectable restorative that is as strong as a rock}

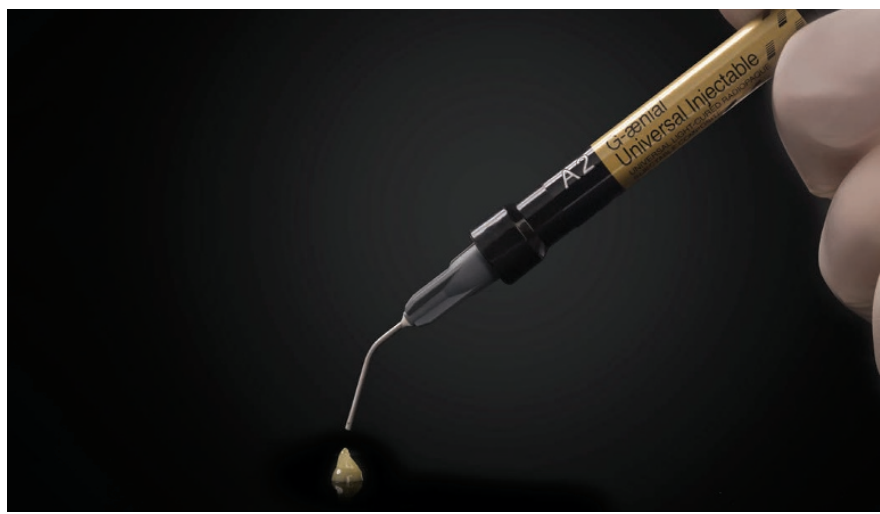

GC's NEW G-aenial Universal Injectable composite range is an easy to use composite restorative material that is as strong as a rock.

Available in 16 shades in three opacities, G-aenial Universal Injectable composite restorative material offers exceptional strength and wear resistance thanks to its combination of ultra-fine Barium fillers and GC's Full-coverage Silane Coating (FSC) technology. Suitable for any cavity class without size limitation, it is strong enough to restore the tooth on its own.

G-aenial Universal Injectable also has a unique thixotropic viscosity which is optimised for freehand build-up of cusps. This means shorter finishing steps are required, saving time, because the anatomy is already created.

Plus, the new syringe design of G-aenial Universal Injectable enables easy extrusion without the mess and inconvenience of uncontrolled flow-out. Whilst the material's viscosity is optimised for easy separation of the material from the tip, the tips themselves feature a long bendable needle for unparalleled access to difficult to reach posterior cavities.

For further information contact GC UK Ltd on 01908 218999, email info@gcukltd.co.uk or visitwww.gceurope.com.

\section{Don't let your patients risk a DIY SOS}

Most of us know the old wives' tales about how you can shortcut your way to better oral health. A very modern concept for the YouTube generation is DIY video guides to filling your own teeth, applying veneers and even giving yourself a whiter smile. But patients need to know that there is a better way.

Saber Tooth White Home Kits from CosTech Dental Laboratory bridge the gap between professional-standard products and the comfort and treatment at home.

They provide a high quality, safe, effective and trusted answer to the problem of discoloured teeth at an affordable price.

If you recommend the Saber Tooth White Home Kit to your patients, they will enjoy the physical and psychological benefits of a healthy-looking open smile.

Don't let your patients risk a DIY SOS! Tell them about Saber Tooth White Home Kits today.

Saber Tooth White Home Kits are available from CosTech Dental Laboratory. For more information, visit www.sabertoothwhite.com.

\section{Award-winning dental instruments}

UK precision dental instrument manufacturer Prima Dental has won a Queen's Award for Enterprise for International Trade in recognition of its outstanding growth in overseas sales over the last three years.
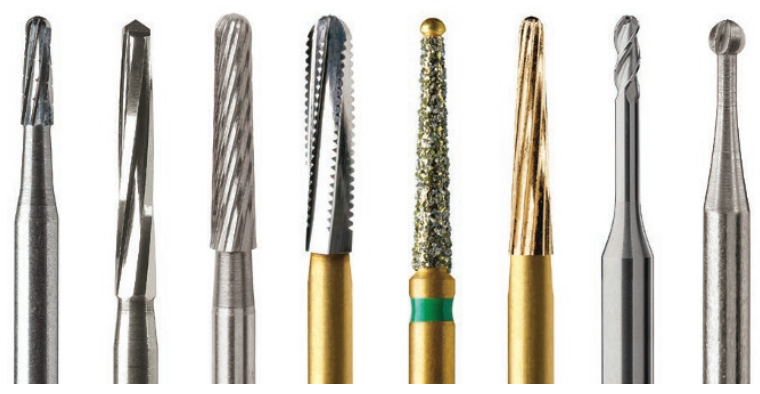

A long-established market leader in carbide and steel dental burs in the UK, Prima Dental also exports precision dental products to 90 countries around the world. From its production facilities in Gloucester, Prima Dental engineers 30 million micron-accurate carbon, diamond and steel dental burs a year.

This is the second Queen's Award for Prima Dental who also won the accolade in 2014.

Today Prima employs 215 staff at its production facility in Gloucester and is set to grow to 250 staff by 2020 .

http://primadental.com/. 